\title{
What do Team Doctors Not Learn at Medical School?
}

ISSN: 2577-1914

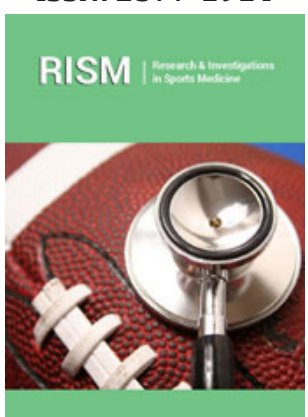

*Corresponding author: Mourad Ghrairi, What do Team Doctors Not Learn at Medical School?

Submission: 㳑 September 27, 2019

Published: 㘹October 11, 2019

Volume 5 - Issue 3

How to cite this article: Mourad Ghrairi . What do Team Doctors Not Learn at Medical School?. Res Inves Sports Med. 5(3). RISM.000614.2019.

DOI: 10.31031/RISM.2019.05.000614

Copyright@ Mourad Ghrairi, This article is distributed under the terms of the Creative Commons Attribution 4.0 International License, which permits unrestricted use and redistribution provided that the original author and source are credited.

\section{Mourad Ghrairi*}

Chief Medical Officer, FIFA Medical Centre of Excellence Dubai Former Doctor of Football clubs and national teams, France, Tunisia \& UAE

\section{Introduction}

Elite level sports are evolving ever so rapidly. Performance requirements are more strenuous for professional athletes who must strive to stay fit and healthy and are therefore constantly monitored by teams of doctors. These doctors are responsible for achieving two seemingly paradoxical goals: Allowing athletes to improve their performance as much as possible while maintaining their health and wellbeing. Therefore, athletes under medical supervision will aim to reach their full potential in optimizing their performance level within the constraints created by their physical and mental health. However, some athletes choose to ignore those constraints and might resort to both long- and short-term solution that can significantly impair their health. These include overtraining and/or doping.

Nowadays, it is necessary to provide athletes with the highest level of medical care. Consequently, sports medicine has been popularized and is necessary at the highest level of any sport. In the most popular sport in the world, soccer, the team doctor is now a full-time employee. How to become a team doctor? What does a prospective sports medicine doctor (then team doctor) learn at medical school? Does sports medicine exist as a separate and unique specialty in med school?

Sports medicine has many unique aspects: it's a medicine of populations rather than physical functions. It navigates two distinct fields: medicine and physical exercise. Overall, it's an evidence-based medicine focused on a fusion of clinical expertise developed throughout a sports medicine doctor's career and scientific findings that emerge from the sports medicine research literature. One of the most aspects of sports medicine doctor's role is to make clear decisions on a player's ability to resume activity after an injury or illness.

The sports medicine doctors must be ready to exercise their skills in a field where no error can be tolerated by the player, coach, manager, club owner, or fans. However, a sports medicine doctor will not receive all the training required for this level of expertise at medical school. This is more so the case in countries where sports medicine is taught as a mere subspecialty. Most medical specialties focus on treating a particular physical function or system of the human body, but it is not the case of sports medicine which focuses on treating a group of individuals and all health concerns related to the exercise of their activity. Sports medicine also takes into consideration the fact that athletes can be subject to developing the same conditions as other normally constituted human beings. This requires that those who practice sports medicine be able to master a knowledge in a wide variety of medical fields such as general medicine, physiology, biology, psychology, nutrition, as well as to develop an understanding of the movement and functioning of the musculoskeletal system and conditions that may affect performance. The complexity of this task is what sets sports medicine apart from other medical disciplines.

Despite the aspect of this discipline, it is taught as a stand-alone specialty in some countries while others teach it merely as a sub-specialty. In either case, the sports medicine doctor learns that his technical-medical role is to manage and prevent injuries, illnesses, emergencies, acclimatization and anti-doping issues as well to contribute in optimizing the athlete's performance. Future team doctors do not learn all these components of their job at medical school. Precisely, they are not taught about their athletes' performances. These 
can only be learned on the field since each athlete is different and each sport is unique. To remedy this difficulty, international sports and sports medicine institutions have created rigorous academic programs aiming to aid health professionals in keeping up with the job and acquiring additional expertise that might not have been acquired at medical school [1]. In addition, FIFA has created a football medicine diploma which is a free online course designed to help doctors to learn how to diagnose and manage common football-related injuries and illnesses. This online training meant to help reinforce the skills acquired in medical school [2]. But there remains a certain part of the team doctor's job that cannot be taught due to the rapidly evolving nature of the discipline as well as new technological advancements of the sports sciences that influence athletic performance and recovery efforts. The idea that some aspects of our job are not learnt at medical school is fundamental to this paper and it was inspired by a presentation entitled "What you did not learn in medical school" and given by Dr Michel D'Hooghe, President of the FIFA Medical Committee [3], at the $5^{\text {th }}$ Congress of the European College of Sports and Exercise Physicians with FIFA update hosted by the FIFA Medical Centre of Dubai in December 2017 [4].

The second aspect of the team doctor's job is rarely taught in medical schools around the world and it is what sets this profession apart from hospital-based specialties. Nowadays, and especially if the sports medicine team doctor operates in the field of professional football, the team doctor needs to understand that they are working within a multi-disciplinary team of physiotherapists, masseurs, nutritionists, psychologists, trainers, sport scientists etc. Efficient and effective communication between these various agents is key to the role and function of a sports medicine doctor. For instance, in the case of an injury to a player, there must be a series of welldefined steps (from injury time until return-to-play) in transmitting information continuously and fluidly between the different agents responsible for the player's well-being and ending with a clear and unified message to the injured player, the head coach as well as to the club's management to avoid any confusion and to define the responsibility of each agent.

Poor communication could generate poor cooperation which is in turn corelated with an increased rate of injuries and reinjuries. This is even more telling for muscular injuries [5,6]. Based on my personal experience as a team doctor on the field, with a multicultural medical and coaching staff, I have noticed that communicating the injury in the language of the staff members avoids confusion and results in a lower rate of injuries and re-injuries [7]. Table 1 below is a summary of my experience working with multilingual coaching staff. Some of them did not speak English and in order to avoid confusion they had to be informed of the type of injury in their respective languages following a common terminology describing a comprehensive diagnosis and its consequence on the estimated period of lay-off of the injured player (usually a source of miscommunication).

Table 1: Translation of common muscle injury terms used by a sports medicine doctor working in soccer.

\begin{tabular}{|c|c|c|c|c|c|c|}
\hline English & cramp & DOMS & tightness & strain & Tear & Rupture \\
\hline Spanish & calambre & agujetas & contractura & elongación & Rotura & ruptura total \\
\hline Portuguese & cãibra & tenso & contratura & estiramento & ruptura parcial & rotura completa \\
\hline Italian & crampo & affaticamento & contrattura & stiramento & strappo & rottura \\
\hline French & crampe & fatigue & contracture & élongation & déchirure & rupture \\
\hline German & krampf & & muskelhärte & zerrung & muskelfaserriss & kompletter rris \\
\hline Dutch & kramp & & stijfheid & verreking & scheur & ruptuur \\
\hline Arabic & شَـد & تَعَب & تَيَبَُس & تَمَلَّد & تَمَزُُق & قَّطع \\
\hline
\end{tabular}

Finally, the team doctor must also be savvy enough administratively to deal with the constraints imposed upon the team by insurance companies as well as keeping up to date with the laws of the game such as anti-doping laws and concussion rules.

After my 25 years of experience as a team doctor with many clubs and national teams on three different continents (Africa, Europe and Asia) I decided to stop practicing sports medicine on the field and I moved to an administrative position as the Chief Medical Officer of the FIFA Medical Centre of Excellence in Dubai. When I meet with fellow sports physicians from around the world, we often share our experiences and we always end up reflecting on the ways we can contribute to the evolution of our field. We also aim to improve the condition of our colleagues in a world where the sports medicine doctors are often subject to the pressure of the technical staff, the club management, the fans, and sometimes the injured player themselves to return to play as quickly as possible. We are interested in determining the ways in which a future team doctor can be properly trained at medical school in order to prepare them for the multiple and varied challenges that they will face in practice and on the field.

\section{Conclusion}

To conclude, as evidenced in this commentary, football medicine will always be a job learned on the job. Indeed, it is a dynamic and continuously evolving field requiring its practitioners to always be a step ahead when it comes to preserving the most important aspect of the sport which is the athlete's health. As Michelangelo appropriately declared at age 87, "Yet, I am learning." 


\section{Acknowledgement}

I would like to thank all my friends and colleagues who have helped in the thought process that guided me through this article:

1. Dr Michel D'Hooghe: President of the FIFA medical committee

2. Pr Fabio Pigozzi: President of the International Federation of Sports Medicine

3. Pr Heinz Lohrer: President of the European College of Sports and Exercise Physicians

4. Dr Massimo Manara: Team doctor of AS Roma Italy

5. Dr Xavier Valle: Team doctor of FC Barcelona Spain

6. Dr Don De Winter: Former team doctor of Ajax Amsterdam Netherlands

7. Dr Tom Looney: MBR University Dubai

Finally, I would like to remember my late friend Luiz Carlos Saroli (Caio Júnior) who, during his tenure as head coach of AL Shabab FC Dubai, has provided me with a tremendous level of support and help when it came to communicating with the coaching staff despite the language barrier.

\section{References}

1. Lyle J, Micheli J, Pigozzi F, Chan M, Frontera W, et al. (2012) Team Physician Manual. ( $3^{\text {rd }} \mathrm{edn}$ ), International Federation of Sports Medicine.

2. Fulcher M (2016-2019) FIFA Football Medicine Diploma.

3. D'Hooghe M (2017) What you did not learn in the medical school, $5^{\text {th }}$ congress of ECOSEP with FIFA update, In: D'Hooghe M \& Ghrairi M (Eds.), Session XI: team physician challenges in 2018 chair, Dubai, United Arab Emirates, pp. 8-9.

4. Malliaropoulos N, Ghrairi, M,Al Hashimi, Padhiar N (2017) Inspiring excellence in musculoskeletal sports medicine. Br J Sports Med 51(22): 1575.

5. Ghrairi M, Loney T, Pruna R, Malliaropoulos N, Valle X (2019) Effect of poor cooperation between coaching and medical staff on muscle reinjury in professional football over 15 seasons Open access journal of sports medicine 2019(10): 107-113.

6. Pruna R (2018) Muscle injury guide-Preventive and treating muscle injuries in football. FC Barcelona innovation hub edition 2018.

7. Ghrairi M, Khelifa M, Sallaoui R, Zerguini AY (2013) Characteristics of Injuries in a Professional Soccer Club of Dubai. Medicine \& Science in Sports \& Exercise 45(5S): 63-66. 